\title{
Macroeconomic Uncertainty and Risk: Collective optimism of small business owners
}

\begin{abstract}
How small business owners assess uncertainty and risk in the macroeconomic environment to formulate optimism towards their business activity is an important research question for both policymakers and academics alike. Drawing on monthly optimism index and a variety of uncertainty and volatility (risk) trackers from January 1986 to March 2020, we find that economic and tax policy uncertainty increase optimism, surprisingly, monetary or fiscal policy, health care policy, or regulatory uncertainty do not impact optimism. Aggregate risk in the markets increases optimism. The findings highlight the positive response to risk in reporting optimism, however, a negative response to uncertainty in reporting optimism among small business owners.
\end{abstract}

\section{Introduction}

The drivers of the economic sentiment of small business owners is of keen interest to policymakers (Dunkelberg \& Wade, 2009; Phillips, 2002). The longest-running small business optimism index is the National Federation of Independent Businesses (NFIB) Small Business Optimism Index, an indicator of the health of young businesses in the US. Released on the second Tuesday of every month, the optimism index reflects the mood of small businesses with a score of 100 as the baseline, that is scores above 100 indicating a positive mood and scores lower than 90 as a signal of recession. Based on the monthly data of hundreds of thousands of small businesses, the optimism index remains among the most reliable proxy of the pulse of the small businesses in the US. Small business owner optimism refers to the greater expectation of positive future events relative to negative future events (Dunkelberg \& Wade, 2009; Storey, 2011).

We take a policy perspective and focus on the collective optimism of business owners, a key index of interest in the broader economy (Anglin, McKenny, \& Short, 2018; Julien, 2018). We focus on the role of two widely assessed elements in entrepreneurshipuncertainty and risk - in driving collective optimism of small business owners (Rakow, 2010). Based on the classical Knightian consideration of uncertainty as an "unknown, unknown" and risk as a "known, unknown," the elements of uncertainty and risk that small 
business owners respond to is an important research question (Knight, 1921). The shared positive beliefs and expectations of a group of individuals are indicative of the expected mood of the collective (Santero \& Westerlund, 1996) and influence future decision making of small business owners considered as engines of economic growth. The collective sentiment is studied widely in assessing consumer, executive, supply chain manager sentiments, among others (Christiansen, Eriksen, \& Møller, 2014; Santero \& Westerlund, 1996). Though individual optimism is partly driven by psychological (Cooper, Woo, \& Dunkelberg, 1988), genetic (Conrad, 2001), or environmental factors (Yuh, Neiderhiser, \& Reiss, 2010), collective optimism of the business owners is not only important to priming economic activity, but it also is a harbinger informing policymakers on the needs of small business owners.

Aggregate small business owner optimism index is an individual-level and grouplevel aggregation of a variety of firm-specific and environmental factors that are combined in an unobserved fashion, making it notoriously difficult to assess and attribute weights to what drives the reporting of optimism index. Uncertainty and risk-related macroeconomic factors that drive the collective optimism have significant estimation challenges. Uncertainty and risk related factors could be correlated and multiple indicators can aggregate in an unobservable fashion. Furthermore, due to a multitude of uncertainty and risk indicators the traditional vector autoregressions or time series econometrics based approaches may be of limited use. An additional limitation is that decision-makers cannot fully explain their evaluation process. One approach to addressing this challenge is to use the Stochastic Multi-Attribute Acceptability Analysis (SMAA), where the small business owner is not able to fully report the parameter necessary for devising the optimism index (Doumpos, Gaganis, \& Pasiouras, 2016; Doumpos, Hasan, \& Pasiouras, 2017).

In this research note, we attempt to address this challenge by using a Bayesian LASSO 
regression model built on the " $\sigma-\mu$ efficiency analysis"1 (Greco, Ishizaka, Tasiou, \& Torrisi, 2019b). We build on prior work by adding the Bayesian aspect to control for priors and using LASSO regression to overcome the challenge of an unobservable combination of attributes across a multitude of indicators. We use the monthly optimism index from NFIB from January 1986 to March 2020 and combine this data with monthly economic policy uncertainty and volatility (risk) tracker. We use both the aggregate and individual dimensions of uncertainty and volatility as we ex-ante do not know how the uncertainty and risk indicators could combine in explaining aggregate optimism index. The LASSO component of the proposed Bayesian LASSO regression model in this paper accommodates these overlapping aggregates.

Our attempt goes beyond an empirical exercise. The findings are also of significant theoretical interest. First, the inference from our analysis is that small business owners negatively weigh economic and tax uncertainty and positively weigh market risk in forming business optimism. The traditional theory in entrepreneurship on risk and uncertainty has focused on positive and negative aspects of these key characteristics, however, we jointly consider these two factors to assess how small business owners manage these tradeoffs in reporting optimism. Despite the associated negative elements of risk that carry a loss proposition, consistent with the assumption of risk aversion among small business owners (Fairlie \& Holleran, 2012), risk (volatility) seems to be associated with higher levels of optimism, however, uncertainty elicits lower optimism.

Second, equally interesting are the findings on the limited role of widely espoused indicators discussed in the popular press. We find that uncertainty in monetary or fiscal policy, health care policy, or regulatory uncertainty has a negligible impact on optimism. Though monetary and fiscal policy uncertainty can impact access to capital or healthcare are also popular when discussing challenges for small business owners (Kitching, 2019; Snowe, 2006)

\footnotetext{
${ }^{1}$ Standard deviation / mean analysis.
} 
these factors do not seem critical to lowering optimism. Though the regulation is considered as an important consideration for small business owners in the US, regulatory uncertainty is not a driver of lower optimism.

Overall, our goal with this research note is two-fold-focus on an important index relevant to entrepreneurship and leverage a methodology that helps overcome several estimation challenges in the uncertainty and risk related drivers of such index. Our primary contribution remains theoretical as we identify an important consideration for policymakersin forming business optimism, small business owners seem to react negatively to uncertainty indicators, but positively to risk indicators in the market. In the following sections, we start by providing a brief background to our study followed by the empirical specification and results. We close after discussing the implications for policymakers and academics.

\section{Theoretical Background}

Since the 1940s, economists have focused on measuring collective sentiment with the underlying premise that the opinions, feelings, and beliefs of the collectives in societal segments could help predict broader changes in the economy. The measure of economic sentiment is not only informative to the policymakers but is also, at times, a leading indicator of the economic cycle. Timely sentiment indices inform policymakers to proactively act towards favorable policies. Among the sentiment indices, NFIB's optimism index represents the longest-running sentiment index of small business owners. The sentiment indices are designed to improve the validity of the measure at the population level, and though idiosyncratic measures are valuable to their business owners, sentiment index aims at improving population-averaged assessment. Therefore, moving from individual business owner optimism assessments studied widely in entrepreneurship literature, we zoom out and focus on the optimism of small business owners' assessment of expected future business 
conditions. A variety of studies have shown that consumer and investor sentiments impact market returns and despite its limitations as aggregate self-reported data, sentiment indices remain critical to macroeconomic decision making (Christiansen et al., 2014).

Small business owners, and entrepreneurs, in particular, are generally optimistic (Crane \& Crane, 2007). Optimism refers to the extent to which the positive expected events of the future outweigh the negative expected events (Scheier \& Carver, 1985). Optimism is an impeller for small business owners facing uncertainties and risks. Though the basis of optimism could be genetic or molded during the formative years of an individual, related to the sentiment index the idiosyncrasies in trait-like optimism is not the primary concern. The sentiment index focuses on the time-varying assessments of the underlying sentiment based on changing macroeconomic conditions. Just as investors or consumers reporting sentiments are driven by a variety of personal and social factors, on the aggregate the goal is to assess the responsiveness of investors and customers to changing economic conditions. Similarly, the NFIB optimism index is based on changing optimism of small business owners with the changing macroeconomic environment. Collective optimism defined as shared positive expectations that outweigh shared negative expectations is previously studied at the team, organizational, community, or national level (Bennett, 2011). Our theoretical assumption, consistent with sentiment indices, is that of an aggregative index (Woehr, Loignon, Schmidt, Loughry, \& Ohland, 2015).

In reacting to changing economic environments, signals of risk and uncertainty are salient. The embedded framing of risk and uncertainty are central to entrepreneurial endeavors (Knight, 1921). Knight (1921) proposed that risk refers to unknown outcomes from known distribution, whereas uncertainties refer to unknown outcomes from unknown distributions. With risk, probabilities can be ascribed to an outcome whereas uncertainty probabilities are unknown. Risk refers to variations in possible outcomes that are known or 
previously experienced whereas uncertainty refers to unexperienced events (Taleb, 2010). Based on bounded rationality (Simon, 1997), though entrepreneurial decision making is not random and irrational, studies have shown that entrepreneurs engage in deliberative decision making by seeking information and support, and by drawing on a variety of tools, including effectuation (Sarasvathy, 2009), search and satisficing (Berg, 2014), navigating institutional environments by building coalitions (Dew, Read, Sarasvathy, \& Wiltbank, 2008), among others. Driven by two mental processes, and intuitive, but error-prone one or the logical one based on "uniformity of nature" (page 230), Knight highlighted that it is correct "to treat all instances of economic uncertainty as cases of choice between a smaller reward more confidently and a larger one less confidently anticipated" (p. 237). The intuitive approach is faster, requires less effort, however, it is subject to errors. The logical approach is cognitively effortful, is rule-based, and driven by conscious attention.

Based on the framing of risk and uncertainty signals in the broader macroeconomy and considering the underlying challenges in processing such signals, a calculus of how multiple signals are interpreted, processed, and aggregated is difficult to ascertain. Therefore, we expect small business owners to be Bayesian learners who update their expectations in the context of their business and evolving macroeconomic signals. As such, Knightian or Kahnemanian's one-shot framing decisions may be less applicable, and a Bayesian approach may be central to developing an understanding of how small business owners interpret uncertainty and risk-based signals to devise optimism sentiment.

The Bayesian approach by itself may not be sufficient in and itself as the cognitive combinations of uncertainty and risk signals are unobservables, and more importantly, small business owners may not be able to report the parameters to weigh these indices. For example, small business owners in the retail industry may consider an aggregate risk index, but may also consider consumer sentiment risk index. The consumer sentiment risk index is a 
part of the aggregate risk index, however, this empirically less desirable attention to aggregate and its components can be expected in practice and the traditional regression models may not suffice. The optimism index may not be based on additive parameter weights, and generally a result of intuitive and less linear thought processes that require accommodation of such errors and also variations in attention to aggregate and components of signals. To accommodate such varying combinations we develop a model based on LASSO with Bayesian priors.

The methodology we offer is not a panacea for addressing the problem of unobservable collation, aggregation, and reporting of optimism sentiment. The proposed Bayesian model with a LASSO prior allows us to lower concerns in understanding which risk or uncertainty signals influence the optimism index. Due to the lack of theoretical background, we do not propose a formal hypothesis, however, our research question is: how do small business owners interpret (positively or negatively) uncertainty and risk-based signals from the macroeconomy?

Next, building on the above discussion, we provide a formal model of our methodology.

\section{Empirical Specification}

Suppose we have a vector of predictors $\boldsymbol{x}_{t} \in \mathbb{R}^{K}$ and a vector of outcomes $\boldsymbol{y}_{t} \in \mathbb{R}^{M}$. A dynamic factor model is as follows.

$$
\begin{gathered}
\boldsymbol{y}_{t}=\Lambda f_{t}+\xi_{t} \\
f_{t}=\varrho f_{t-1}+\boldsymbol{x}^{\prime}{ }_{t} \boldsymbol{\gamma}+\zeta_{t}, t=1, \ldots, n
\end{gathered}
$$

where $\Lambda$ is a vector $M \times 1$ of factor loadings, $\xi_{t}$ is an $M \times 1$ vector of error terms, $\zeta_{t}$ is the error term of the factor equation, $f_{t}$ is the dynamic factor, and $\varrho, \gamma$ are unknown coefficients in $\mathbb{R}$ and $\mathbb{R}^{K}$ respectively.

In many instances, we want to infer the effect of predictors on outcomes via a composite 
indicator such as

$$
C_{t}=\boldsymbol{y}_{t}^{\prime} \boldsymbol{w}, t=1, \ldots, n
$$

where $\boldsymbol{w} \in \mathbb{S}=\left\{w \in \mathbb{R}_{+}^{M}: \sum_{m=1}^{M} w_{j}=1\right\}$. Then the problem becomes how to estimate the effect of predictors $\boldsymbol{x}_{t}$ on the composite indicator $C_{t}$. If the weights were known one could use least squares (LS) in the following regression.

$$
\boldsymbol{y}_{t}^{\prime} \boldsymbol{w}=\boldsymbol{x}_{t}^{\prime} \boldsymbol{b}+e_{t}, t=1, \ldots, n
$$

where $e_{t}$ is an error term, and $\boldsymbol{b} \in \mathbb{R}^{K}$ is a vector of associated coefficients estimates by LS. As the coefficients $\boldsymbol{w}$ are unknown this procedure does not work. Instead, we propose to

$$
\boldsymbol{y}_{t}^{\prime} \boldsymbol{w}=y_{t}^{*}+\varepsilon_{t}
$$

where $\varepsilon_{t}$ is an error term, and $y_{t}^{*}$ is, essentially, the value of the composite indicator $C_{t}$ in (2) so we may refer to it as a modified composite indicator.

Greco, Ishizaka, Tasiou, and Torrisi (2019a) introduce a methodology for constructing composite indicators known as " $\sigma-\mu$ efficiency analysis". Many international organizations use equal weights in the construction of composite indicators. This is associated with another major problem, viz. the problem of "representative agent", which can be mitigated by the use of multi-criteria decision analysis and Stochastic Multi-Attribute Acceptability Analysis (SMAA). SMAA involves a decision-maker that is unable to provide the parameters required for the evaluation process (see e.g., Doumpos et al., 2016; Doumpos et al., 2017; as well as, Greco, Figueira, \& Ehrgott, 2016; Greco, Ishizaka, Tasiou, \& Torrisi, 2019a; Greco, Mousseau, \& Słowiński, 2008) (see e.g. Doumpos et al., 2016, 2017, as well as Greco et al., 2008, 2010, 2016, 2019b). As Greco et al. (2019b) write: “More specifically, by considering a probability distribution on the set of feasible weight vectors, SMAA reveals the probability that a unit attains a given ranking position, as well as the probability that a given unit is better than another" (p. 943). If desired, the decision-maker can prioritize the weights, for example $w_{1} \leq$ $\cdots \leq w_{M}$. Tsionas (2020) showed how the analysis in Greco et al. (2019b) can be cast into a 
Bayesian framework.

\section{Model}

Our model consists of (5) plus the following.

$$
y_{t}^{*}=\rho y_{t-1}^{*}+\boldsymbol{x}_{t}^{\prime} \boldsymbol{\beta}+v_{t},
$$

where $v_{t}$ is an error term, and $\boldsymbol{\beta} \in \mathbb{R}^{K}$ is a vector of unknown coefficients. Notice that $y_{t}^{*}$ does not have the same interpretation as the dynamic common factor $f_{t}$ in (1). The common factor is a "representative" variable of the $\boldsymbol{y}_{t} \mathrm{~s}$ whereas $y_{t}^{*}$ is a linear combination of the $\boldsymbol{y}_{t} \mathrm{~s}$ that allows imposition of prior notions of importance and, in any case, it can be interpreted better as a "dynamic canonical correlation" for lack of a better name.

As our predictors are economic policy variables and our outcomes are entrepreneurshiprelated variables, we modify (5) as follows.

$$
y_{t}^{*}=\rho y_{t-1}^{*}+\boldsymbol{x}_{t}^{\prime} \boldsymbol{\beta}+v_{t}-u_{t}
$$

where $u_{t} \geq 0$ is a random variable representing inefficiency on how economic policy affects entrepreneurship. Economic policies are not always designed optimally and the very notion of an "optimal" economic policy is ambiguous. Equation (6) provides a way to summarize the effect of policy variables $\boldsymbol{x}_{t}$ on the dynamic composite indicator $y_{t}^{*}$ and, at the same time, figure out where economic policy introduces systematic inefficiencies in entrepreneurial performance. We make the following distributional assumptions:

$$
\begin{gathered}
\varepsilon_{t}\left|x_{t} \sim \mathcal{N}\left(0, \sigma_{\varepsilon}^{2}\right), v_{t}\right| x_{t} \sim \mathcal{N}\left(0, \sigma_{v}^{2}\right), \\
\ln u_{t}=\psi_{o}+\psi \ln u_{t-1}+x^{\prime}{ }_{t} \boldsymbol{\gamma}+\eta_{t}, \\
\eta_{t} \mid x_{t} \sim \mathcal{N}\left(0, \sigma_{u}^{2}\right) .
\end{gathered}
$$

We denote all observed data by $\boldsymbol{Y}=\left\{\boldsymbol{y}_{t}, \boldsymbol{x}_{t}\right\}_{t=1}^{n}$.

The major assumption in (7) is that policy-related inefficiency is dynamic and also depends on the policy variables $\boldsymbol{x}_{t}$. Moreover $\psi_{o}, \psi$ and $\boldsymbol{\gamma} \in \mathbb{R}^{K}$ are unknown coefficients. This model allows to figure out the effect of policy variables $\boldsymbol{x}_{t}$ on both the modified dynamic 
composite indicator $y_{t}^{*}$ as well as on policy-induced entrepreneurial inefficiencies.

When the number $K$ of predictors $\boldsymbol{x}_{t}$ is large relative to sample size (in our application we have $K=56$ which produces 112 parameters in the indicator and inefficiency equations plus two dynamic parameters and the scale parameters). So, $K$ is roughly $1 / 4$ of our sample size which is not excessive but we would like, nevertheless, to restrict the number of predictors whose effect is near zero. This is accomplished by using a Least Absolute Selection and Shrinkage Operator (LASSO) prior (Bae \& Mallick, 2004; Figueiredo, 2003; Park \& Casella, 2008; Tibshirani, 1996; Yuan \& Lin, 2005).

To our knowledge, this is the first instance in which a LASSO prior is placed on a dynamic latent variable model including both the latent dynamic modified composite indicator $\left(y_{t}^{*}\right)$ and latent dynamic inefficiency $\left(u_{t}\right)$.

Denote collectively all regression - like parameters by $\boldsymbol{\alpha}=\left[\boldsymbol{\beta}^{\prime}, \boldsymbol{\gamma}^{\prime}\right]^{\prime} \in \mathbb{R}^{d}$ where $d=$ $2 K$. Then, the LASSO prior has the following form:

$$
\boldsymbol{\alpha} \mid \boldsymbol{\tau}=\left[\tau_{1}, \ldots, \tau_{d}\right]^{\prime} \sim \mathcal{N}_{d}\left(\mathbf{0}_{d}, \boldsymbol{D}_{\boldsymbol{\tau}}\right),
$$

where $\boldsymbol{D}_{\boldsymbol{\tau}}=\operatorname{diag}\left[\tau_{1}^{2}, \ldots, \tau_{d}^{2}\right]$ denotes a diagonal matrix with elements $\tau_{1}, \ldots, \tau_{d}$ along its main diagonal, and

$$
p(\boldsymbol{\tau}) \propto \prod_{j=1}^{d} \frac{\lambda}{2} \exp \left\{-\lambda \tau_{j}^{2}\right\} .
$$

Here, $\lambda$ is a smoothing parameter. Posterior conditional parameters of $\boldsymbol{\alpha}, \boldsymbol{\tau}, \lambda$ are in standard families so Gibbs sampling can be performed efficiently. Our prior for $\lambda$ is $p(\lambda) \propto$ $\lambda^{-1}$ yielding the conditional posterior $p(\lambda \mid \tau, Y) \propto \lambda^{d-1} \exp \left\{-\lambda \sum_{j=1}^{d} \tau_{j}^{2}\right\}$ which is a gamma distribution, $G\left(d, \boldsymbol{\tau}^{\prime} \boldsymbol{\tau}\right)$ (notice that as we remarked before $\boldsymbol{Y}$ denotes all available data). For a linear regression of the form $\boldsymbol{y}=\boldsymbol{X} \boldsymbol{b}+\boldsymbol{v}$ the LASSO would minimize the objective function 


$$
\begin{aligned}
\min _{\beta} \quad(\boldsymbol{y}-\boldsymbol{X} \boldsymbol{b})^{\prime}(\boldsymbol{y}-\boldsymbol{X} \boldsymbol{b})+\sqrt{\lambda} \cdot \sum_{j=1}^{d}\left|b_{j}\right| \\
=(y-X \beta)^{\prime}(y-X \beta)+\sqrt{\lambda} \cdot\|\boldsymbol{b}\|_{1},
\end{aligned}
$$

for $\lambda>0$ and $\|\boldsymbol{b}\|_{1}$ is the $L_{1}$-norm of the vector of regression parameters.

Our MCMC techniques are detailed in Appendix A.

\section{Data and Methods}

We use three datasets: (i) the Small Business Optimism Index from NFIB; (ii) the categorical policy uncertainty data (a proxy for uncertainty); and (iii) categorical volatility index data (a proxy for risk). All data are monthly data from January 1986 to March 2020.

The NFIB index is comprised of responses from small business owners on prevailing economic conditions. The index comprises of 10 components and net figures for seasonallyadjusted optimism are derived from subtracting negative responses from positive responses on business expectations and seasonally adjusted. The components of the NFIB index are listed in Online Appendix B.

The categorical policy uncertainty data is from Baker et al. () and is based on a range of sub-indices based on results from the Access World News database of over 2,000 US newspapers. Each subindex is based on terms related to economy, uncertainty, and policy. The time series is multiplicatively normalized to have a mean of 100 . We provide the list of all the categories in Online Appendix C. The index is the most comprehensive monthly index and has been used in a variety of recent studies.

The categorical data for volatility index is a newspaper based Equity Market Volatility (EMV) tracker that moves with the CBOE Volatility Index (VIX) and with the realized volatility of returns on the S\&P 500. The policy-related economic EMV tracker is created for 30 categories every month from January 1985 to the present. The details on the 
30-categories are listed in Online Appendix D, and additional details on the calculation of the measure are available at https://www.policyuncertainty.com/EMV_monthly.html.

\section{Results}

Posterior means and standard deviations of all parameters are reported in Table 1 and Figure 1. In Table E.1 of Online Appendix E, we report the results of estimating the dynamic factor model in (1) using maximum likelihood state-space models. Posterior mean estimates of the modified composite indicator are shown in Figure 2. Figure 3 presents the sample distribution of posterior mean estimates of inefficiency.

Insert Tables 1-2 and Figures 1-3 about here

Our inferences are based on Table 2. Before discussing the results we reiterate that inclusion of combined and individual dimensions is not subject to multicollinearity concerns in LASSO estimates. Related to past idiosyncrasies in mean estimation $\rho$ is controlled for and also to control past errors in combinations to derive optimism index, $\psi$, is controlled for. In interpreting the coefficients, a positive coefficient for $y_{t}^{*}$ the equation is based on interpreted as a typical regression estimate, whereas the estimate of inefficiency equation represents the variation in deriving estimates (that is, inefficiency in aggregating $y_{t}^{*}$ ).

Related to uncertainty signals, economic policy uncertainty lowers optimism (-0.082), however, there is also greater variability in how economic uncertainty is perceived (inefficiency $=0.121)$. Similarly, tax-related uncertainty has a higher correspondence with optimism (-0.093) and a much smaller variability (=0.034). Surprisingly monetary or fiscal policy does not influence optimism and neither does healthcare policy, especially given the lack of insurance for self-employed and insurance as a key consideration for small firm 
employees. Regulation lowers optimism by a small amount, however, financial regulation increases optimism by a small amount.

Related to risk signals, policy-related EMV tracker has a significant correspondence $(=0.344)$ with optimism, followed by Macro-Business Investment and Sentiment EMV Tracker (=0.313, with small inefficiency), however, Macro-Consumer Spending and Sentiment EMV Tracker has a positive correspondence with optimism $(=0.355$, and with lower inefficiency $=-0.162$ ). Several other trackers of volatility have small to negligible correspondence with optimism.

Overall, related to uncertainty, business owners respond negatively to economic policy uncertainty and tax uncertainty. Related to risk, stock market volatility increases optimism, specifically, with Macro - Business Investment and Sentiment EMV Tracker and Macro - Consumer Spending and Sentiment EMV Tracker.

\section{Conclusion}

For this research note, our goals were two-fold—delving into drivers of optimism among small business owners and assessing how business owner optimism is driven by risk and uncertainty. The proposed estimation approach lowers concerns for prior learning by modeling for Bayesian estimates and accounts for unobserved considerations of aggregate and component-based dimensions (LASSO). The findings have the following theoretical implications.

First, the assessment of indices in entrepreneurship could consider the value of the proposed estimation approach. With decision contexts marred by uncertainty, risk, and idiosyncrasies, in words of Knight (as quoted in Rakow (2010)):

"The ordinary decisions of life are made on the basis of 'estimates' of a crude and superficial character. In general the future situation in relation to which we act depends upon the behavior of an indefinitely large number of objects, and is influenced by so 
many factors that no real effort is made to take account of them all, much less to estimate and summate their separate significances. It is only in very special and crucial cases that anything like a mathematical (exhaustive and quantitative) study can be made.” (1921, pp. 210-211)

The quote from Knight is crucial in considering how entrepreneurs consider, report, and aggregate risk and uncertainty related signals. Our approach is a preliminary attempt to model some of the limitations in such aggregates to provide a nuanced view of entrepreneurial response to risk and uncertainty in developing an optimistic outlook. The aggregate mental calculus of developing optimism index could be based on collective intuitions, contagion, or herding or any other group phenomenon. However, such mechanisms are difficult to measure and are intractable. Our estimation has its limitations, however, we focus on the collective aggregations to understand the associations among the components and we do not attempt to address the process of aggregation. Our approach complements Anglin et al. (2018) approach at the individual-industry level factors and focuses on risk and uncertainty indicators driving small business optimism index that is widely disseminated and representative of respondents from a variety of industries and regions.

Second, risk and uncertainty are studied, mostly, separately in the entrepreneurship literature (cf. Koudstaal, Sloof, \& Van Praag, 2016). Devised as "unknown, unknown," and "known, unknown," literature streams on uncertainty and risk have developed mostly on separate trajectories. For example, effectuation can be considered a mode of uncertainty resolution, whereas alertness could be a mode for opportunity search based on the available distribution of information in the Kirznerian framework. In our model, we relax the assumption by considering both risk and uncertainty related signals as they co-occur in an economy in a variety of indicators. Our measures of uncertainty and risk are based on recently developed widely used measures. Broadly the results demonstrate that small business owners have lower 
optimism under uncertainty, but higher optimism for risky signals from the economy.

Third, the findings have implications for policymakers focused on the role of multiple indicators that may calibrate small business sentiment. In addition to the significance of the effects, also of importance is the non-significance of the multitude of indicators in the results. Several of the indicators, including health care, labor laws, environmental regulations are not salient in driving optimism. Based on methodologies such as ours perhaps calibration of small business owner optimism with other observable macroeconomic indicators can be useful.

Our study is not without limitations. We draw on US-based optimism index, however, due to variations in cultural and institutional dimensions the findings may not be generalizable. We draw upon and build over a recent method on the mean-efficiency index to assess how the aggregation of composite indicators can be better modeled. Nevertheless, future studies can develop models. For example, $\sigma-\mu$ efficiency analysis can be applied in addition to the latent variable models we use here if individual responses are available. ${ }^{2}$ This might be important as it would allow us to classify firms in the $\sigma-\mu$ space and determine policy effectiveness more precisely. Additionally, our models can be related (directly, more or less) to the "multiple causes blessing" model of Wang and Blei (2019) and establish causal relations with more precision. Finally, we used newspaper based uncertainty and risk measures that are publicly available and used in several studies. However, future studies could also use survey-based measures or richer measures based on text-analysis from alternate sources including social media.

In closing, based on monthly optimism index and uncertainty and volatility trackers over 34 years we found that economic and tax policy uncertainty and tax uncertainty increased optimism, surprisingly, monetary or fiscal policy, health care policy, or regulatory uncertainty

\footnotetext{
${ }^{2}$ Based on communication with Holly Wade and Andrew Heritage at NFIB, we note though NFIB has the individual estimates, these are not released and also not available through a data user agreement.
} 
did not impact optimism. Aggregate volatility, representing risk in the markets increases

optimism. For small business owners, the findings highlight the positive response to risk, however, a negative response to uncertainty.

\section{References}

Altmann, Y., McLaughlin, S., \& Dobigeon, N. (2014). Sampling from a multivariate Gaussian distribution truncated on a simplex: a review. Paper presented at the 2014 IEEE Workshop on Statistical Signal Processing (SSP).

Anglin, A. H., McKenny, A. F., \& Short, J. C. (2018). The impact of collective optimism on new venture creation and growth: A social contagion perspective. Entrepreneurship Theory and Practice, 42(3), 390-425.

Bae, K., \& Mallick, B. K. (2004). Gene selection using a two-level hierarchical Bayesian model. Bioinformatics, 20(18), 3423-3430.

Bennett, O. (2011). Cultures of optimism. Cultural Sociology, 5(2), 301-320.

Berg, N. (2014). Success from satisficing and imitation: Entrepreneurs' location choice and implications of heuristics for local economic development. Journal of Business Research, 67(8), 1700-1709.

Christiansen, C., Eriksen, J. N., \& Møller, S. V. (2014). Forecasting US recessions: The role of sentiment. Journal of Banking \& Finance, 49, 459-468.

Conrad, P. (2001). Genetic optimism: Framing genes and mentalillness in the news. Culture, medicine and psychiatry, 25(2), 225-247.

Cooper, A. C., Woo, C. Y., \& Dunkelberg, W. C. (1988). Entrepreneurs' perceived chances for success. Journal of business venturing, 3(2), 97-108.

Crane, F. G., \& Crane, E. C. (2007). Dispositional optimism and entrepreneurial success. The Psychologist-Manager Journal, 10(1), 13-25.

Dew, N., Read, S., Sarasvathy, S. D., \& Wiltbank, R. (2008). Outlines of a behavioral theory of the entrepreneurial firm. Journal of Economic Behavior \& Organization, 66(1), 3759.

Doumpos, M., Gaganis, C., \& Pasiouras, F. (2016). Bank diversification and overall financial strength: International evidence. Financial Markets, Institutions \& Instruments, 25(3), 169-213.

Doumpos, M., Hasan, I., \& Pasiouras, F. (2017). Bank overall financial strength: Islamic versus conventional banks. Economic Modelling, 64, 513-523.

Dunkelberg, W. C., \& Wade, H. (2009). NFIB small business economic trends. National Federation of Independent Business. September, 5, 19.

Fairlie, R. W., \& Holleran, W. (2012). Entrepreneurship training, risk aversion and other personality traits: Evidence from a random experiment. Journal of Economic Psychology, 33(2), 366-378.

Figueiredo, M. A. (2003). Adaptive sparseness for supervised learning. IEEE transactions on pattern analysis and machine intelligence, 25(9), 1150-1159.

Greco, S., Figueira, J., \& Ehrgott, M. (2016). Multiple criteria decision analysis: Springer.

Greco, S., Ishizaka, A., Tasiou, M., \& Torrisi, G. (2019a). On the methodological framework of composite indices: A review of the issues of weighting, aggregation, and robustness. Social Indicators Research, 141(1), 61-94.

Greco, S., Ishizaka, A., Tasiou, M., \& Torrisi, G. (2019b). Sigma-Mu efficiency analysis: A methodology for evaluating units through composite indicators. European Journal of 
Operational Research, 278(3), 942-960.

Greco, S., Mousseau, V., \& Słowiński, R. (2008). Ordinal regression revisited: multiple criteria ranking using a set of additive value functions. European Journal of Operational Research, 191(2), 416-436.

Julien, P.-A. (2018). The state of the art in small business and entrepreneurship: Routledge.

Kitching, J. (2019). Regulatory reform as risk management: Why governments redesign micro company legal obligations. International Small Business Journal, 37(4), 395416.

Knight, F. H. (1921). Risk, uncertainty and profit. New York: Houghton-Mifflin.

Koudstaal, M., Sloof, R., \& Van Praag, M. (2016). Risk, uncertainty, and entrepreneurship: Evidence from a lab-in-the-field experiment. Management Science, 62(10), 28972915.

Park, T., \& Casella, G. (2008). The bayesian lasso. Journal of the American Statistical Association, 103(482), 681-686.

Phillips, G. M. (2002). Four leading economic confidence measures: Who's optimism matters? The Journal of Business Forecasting, 21(4), 22.

Rakow, T. (2010). Risk, uncertainty and prophet: The psychological insights of Frank H. Knight. Judgment and Decision Making, 5(6), 458.

Santero, T., \& Westerlund, N. (1996). Confidence Indicators and Their Relationship to Changes in Economic Activity: OECD Publishingo. Document Number)

Sarasvathy, S. D. (2009). Effectuation: Elements of entrepreneurial expertise: Edward Elgar Publishing.

Scheier, M. F., \& Carver, C. S. (1985). Optimism, coping, and health: assessment and implications of generalized outcome expectancies. Health psychology, 4(3), 219.

Simon, H. A. (1997). Models of bounded rationality: Empirically grounded economic reason (Vol. 3): MIT press.

Snowe, O. J. (2006). Small Business Health Plans: A Critical Step in Solving the Small Business Health Care Crisis. Harv. J. on Legis., 43, 231.

Storey, D. J. (2011). Optimism and chance: The elephants in the entrepreneurship room. International Small Business Journal, 29(4), 303-321.

Taleb, N. N. (2010). Why did the Crisis of 2008 Happen? Available at SSRN 1666042.

Tibshirani, R. (1996). Regression shrinkage and selection via the lasso. Journal of the Royal Statistical Society: Series B (Methodological), 58(1), 267-288.

Tsionas, M. G. (2020). A Note on Sigma-Mu Efficiency Analysis as a Methodology for Evaluating Units through Composite Indicators. European Journal of Operational Research.

Wang, Y., \& Blei, D. M. (2019). The blessings of multiple causes. Journal of the American Statistical Association(just-accepted), 1-71.

Woehr, D. J., Loignon, A. C., Schmidt, P. B., Loughry, M. L., \& Ohland, M. W. (2015). Justifying aggregation with consensus-based constructs: A review and examination of cutoff values for common aggregation indices. Organizational Research Methods, 18(4), 704-737.

Yuan, M., \& Lin, Y. (2005). Efficient empirical Bayes variable selection and estimation in linear models. Journal of the American Statistical Association, 100(472), 1215-1225.

Yuh, J.-I., Neiderhiser, J. M., \& Reiss, D. (2010). Genetic and environmental influences on dispositional optimism and depressive symptoms in adolescence. International journal of human ecology, 11(2), 15-23. 
Table 1. Posterior moments of $w$

\begin{tabular}{lcc}
\hline & Post. mean & Post. s.d. \\
\hline Optimism index & 0.419 & 0.0383 \\
Plans to Increase Employment & 0.064 & 0.0039 \\
Plans to Make Capital Outlays & 0.067 & 0.0083 \\
Plans to Increase Inventories & 0.050 & 0.0086 \\
xpect Economy to Improve & 0.165 & 0.0089 \\
Expect Real Sales Higher & 0.144 & 0.0089 \\
Current Inventory & 0.019 & 0.0016 \\
Current Job Openings & 0.058 & 0.0043 \\
Expected Credit Conditions & 0.036 & 0.0028 \\
Now a Good Time to Expand & 0.079 & 0.0054 \\
Earnings Trends & 0.096 & 0.0052 \\
\hline
\end{tabular}


Table 2. Posterior moments of $\beta$ and $\gamma$

\begin{tabular}{|c|c|c|}
\hline & $y_{t}^{*}$ equation & $\begin{array}{c}\text { Inefficiency } \\
\text { equation }\end{array}$ \\
\hline$\rho$ & $\begin{array}{c}0.714 \\
(0.016)\end{array}$ & - \\
\hline$\psi$ & - & $\begin{array}{c}0.818 \\
(0.019)\end{array}$ \\
\hline Economic Policy Uncertainty & $\begin{array}{l}-0.082 \\
(0.011)\end{array}$ & $\begin{array}{c}0.121 \\
(0.015)\end{array}$ \\
\hline Monetary policy & $\begin{array}{c}0.0032 \\
(0.0004)\end{array}$ & $\begin{array}{c}0.004 \\
(0.001)\end{array}$ \\
\hline Fiscal Policy (Taxes OR Spending) & $\begin{array}{c}0.0040 \\
(0.0010)\end{array}$ & $\begin{array}{c}0.017 \\
(0.0021)\end{array}$ \\
\hline Taxes & $\begin{array}{l}-0.093 \\
(0.006)\end{array}$ & $\begin{array}{c}0.034 \\
(0.005)\end{array}$ \\
\hline Government spending & $\begin{array}{c}0.0015 \\
(0.0003)\end{array}$ & $\begin{array}{c}0.017 \\
(0.006)\end{array}$ \\
\hline Health care & $\begin{array}{l}-0.0032 \\
(0.0011)\end{array}$ & $\begin{array}{l}-0.013 \\
(0.002)\end{array}$ \\
\hline National security & 0.0000 & $\begin{array}{r}-0.0032 \\
(0.001)\end{array}$ \\
\hline Entitlement programs & 0.0000 & $\begin{array}{l}0.0044 \\
(0.001)\end{array}$ \\
\hline Regulation & $\begin{array}{c}-0.014 \\
(0.0005)\end{array}$ & $\begin{array}{c}0.0052 \\
(0.0013)\end{array}$ \\
\hline Financial Regulation & $\begin{array}{c}0.017 \\
(0.003)\end{array}$ & $\begin{array}{l}-0.0033 \\
(0.0012)\end{array}$ \\
\hline Trade policy & 0.0000 & $\begin{array}{l}-0.0052 \\
(0.0013)\end{array}$ \\
\hline Sovereign debt, currency crises & $\begin{array}{c}-0.0144 \\
(0.003)\end{array}$ & $\begin{array}{l}0.0255 \\
(0.007)\end{array}$ \\
\hline Overall EMV Tracker & $\begin{array}{c}0.344 \\
(0.021)\end{array}$ & 0.0000 \\
\hline Policy-Related EMV Tracker & $\begin{array}{c}0.174 \\
(0.021)\end{array}$ & 0.0000 \\
\hline Macroeconomic News and Outlook EMV Tracker & 0.0000 & $\begin{array}{c}0.0014 \\
(0.0002)\end{array}$ \\
\hline Macro - Broad Quantity Indicators EMV Tracker & 0.0000 & $\begin{array}{l}0.0035 \\
(0.001)\end{array}$ \\
\hline Macro - Inflation EMV Indicator & $\begin{array}{l}-0.022 \\
(0.006)\end{array}$ & $\begin{array}{c}0.035 \\
(0.006)\end{array}$ \\
\hline Macro - Interest Rates EMV Tracker & $\begin{array}{l}-0.014 \\
(0.002)\end{array}$ & $\begin{array}{c}0.012 \\
(0.003)\end{array}$ \\
\hline Macro - Other Financial Indicators EMV Tracker & 0.0000 & $\begin{array}{c}0.044 \\
(0.016)\end{array}$ \\
\hline Macro - Labor Markets EMV Tracker & $\begin{array}{l}-0.0032 \\
(0.0013)\end{array}$ & $\begin{array}{c}0.0017 \\
(0.0005)\end{array}$ \\
\hline Macro - Real Estate Markets EMV Tracker & 0.0000 & $\begin{array}{l}-0.0013 \\
(0.0002)\end{array}$ \\
\hline Macro - Trade EMV Tracker & $\begin{array}{c}0.0044 \\
(0.0010)\end{array}$ & 0.0000 \\
\hline Macro - Business Investment and Sentiment EMV Tracker & $\begin{array}{c}0.313 \\
(0.015)\end{array}$ & $\begin{array}{l}-0.022 \\
(0.006)\end{array}$ \\
\hline Macro - Consumer Spending and Sentiment EMV Tracker & $\begin{array}{c}0.355 \\
(0.018)\end{array}$ & $\begin{array}{l}-0.162 \\
(0.023)\end{array}$ \\
\hline Commodity Markets EMV Tracker & 0.0000 & 0.0000 \\
\hline Financial Crises EMV Tracker & $\begin{array}{l}-0.014 \\
(0.002)\end{array}$ & $\begin{array}{c}0.022 \\
(0.004)\end{array}$ \\
\hline Exchange Rates EMV Tracker & 0.0000 & $\begin{array}{c}0.0044 \\
(0.0012)\end{array}$ \\
\hline
\end{tabular}


Healthcare Matters EMV Tracker

\begin{tabular}{|c|c|}
\hline 0.0000 & $\begin{array}{c}0.0013 \\
(0.0004)\end{array}$ \\
\hline 0.0000 & 0.0000 \\
\hline 0.0000 & $\begin{array}{c}0.0022 \\
(0.0005)\end{array}$ \\
\hline 0.0000 & 0.0000 \\
\hline 0.0013 & 0.0012 \\
\hline$(0.0002)$ & $(0.0005)$ \\
\hline 0.0000 & $\begin{array}{c}0.0022 \\
(0.0019)\end{array}$ \\
\hline-0.044 & 0.032 \\
\hline$(0.005)$ & $(0.007)$ \\
\hline 0.0000 & $\begin{array}{c}0.041 \\
(0.013)\end{array}$ \\
\hline 0.0000 & $\begin{array}{l}0.0014 \\
(0.001)\end{array}$ \\
\hline 0.0000 & 0.0000 \\
\hline 0.0000 & $\begin{array}{c}0.0144 \\
(0.003)\end{array}$ \\
\hline $\begin{array}{c}0.0044 \\
(0.0012)\end{array}$ & $\begin{array}{c}-0.0032 \\
(0.0011)\end{array}$ \\
\hline 0.0000 & $\begin{array}{c}0.0022 \\
(0.0004)\end{array}$ \\
\hline $\begin{array}{c}0.0032 \\
(0.0004)\end{array}$ & 0.0000 \\
\hline 0.0000 & 0.0000 \\
\hline 0.0000 & 0.0000 \\
\hline-0.014 & 0.017 \\
\hline$(0.004)$ & $(0.005)$ \\
\hline 0.0000 & 0.0000 \\
\hline 0.0000 & 0.0000 \\
\hline 0.0000 & 0.0000 \\
\hline 0.0000 & 0.0000 \\
\hline 0.0000 & 0.0000 \\
\hline 0.0014 & 0.0000 \\
\hline$(0.0002)$ & \\
\hline-0.0013 & 0.0000 \\
\hline$(0.0003)$ & \\
\hline 0.0000 & 0.0000 \\
\hline 0.0000 & 0.0000 \\
\hline 0.0041 & 0.0000 \\
\hline$(0.0013)$ & \\
\hline 0.0000 & 0.0000 \\
\hline 0.0000 & 0.0000 \\
\hline
\end{tabular}

Litigation Matters EMV Tracker

Competition Matters EMV Tracker

Labor Disputes EMV Tracker

Intellectual Property Matters EMV Tracker

$0.0013 \quad 0.0012$

Fiscal Policy EMV Tracker

Taxes EMV Tracker

Government Spending, Deficits, and Debt EMV Tracker

0.041

Entitlement and Welfare Programs EMV Tracker

0.0014

Monetary Policy EMV Tracker

Regulation EMV Tracker

0.0144

Financial Regulation EMV Tracker

Competition Policy EMV Tracker

Intellectual Property Policy EMV Tracker

Labor Regulations EMV Tracker

Immigration EMV Tracker

Energy and Environmental Regulation EMV Tracker

Lawsuit and Tort Reform, Supreme Court Decisions EMV Tracker

Housing and Land Management EMV Tracker

Agricultural Policy EMV Tracker

0.0000

Notes: Zero entries mean that the respective coefficients are zero as we use a LASSO prior. 
Figure 1. Marginal posterior densities of $w$

(a)

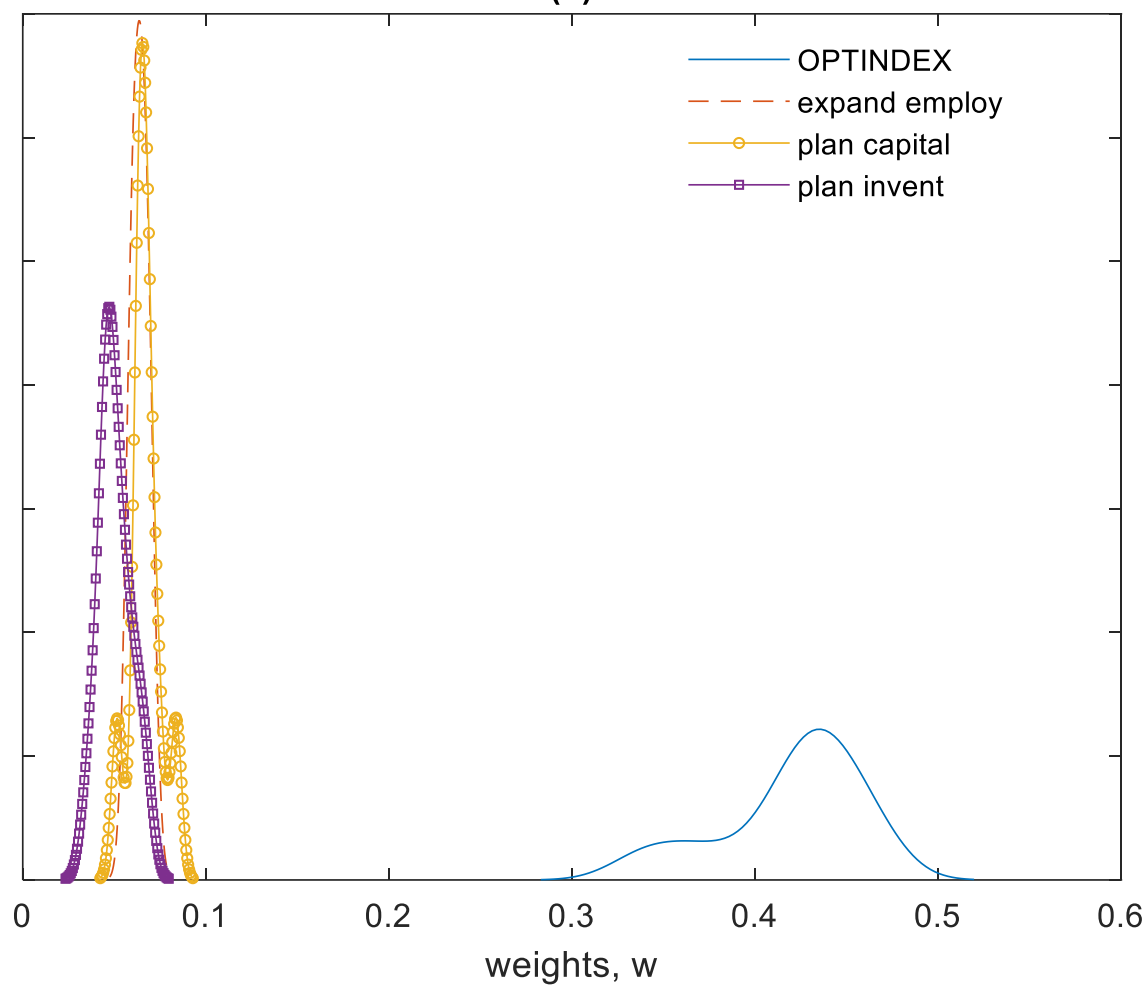

(b)

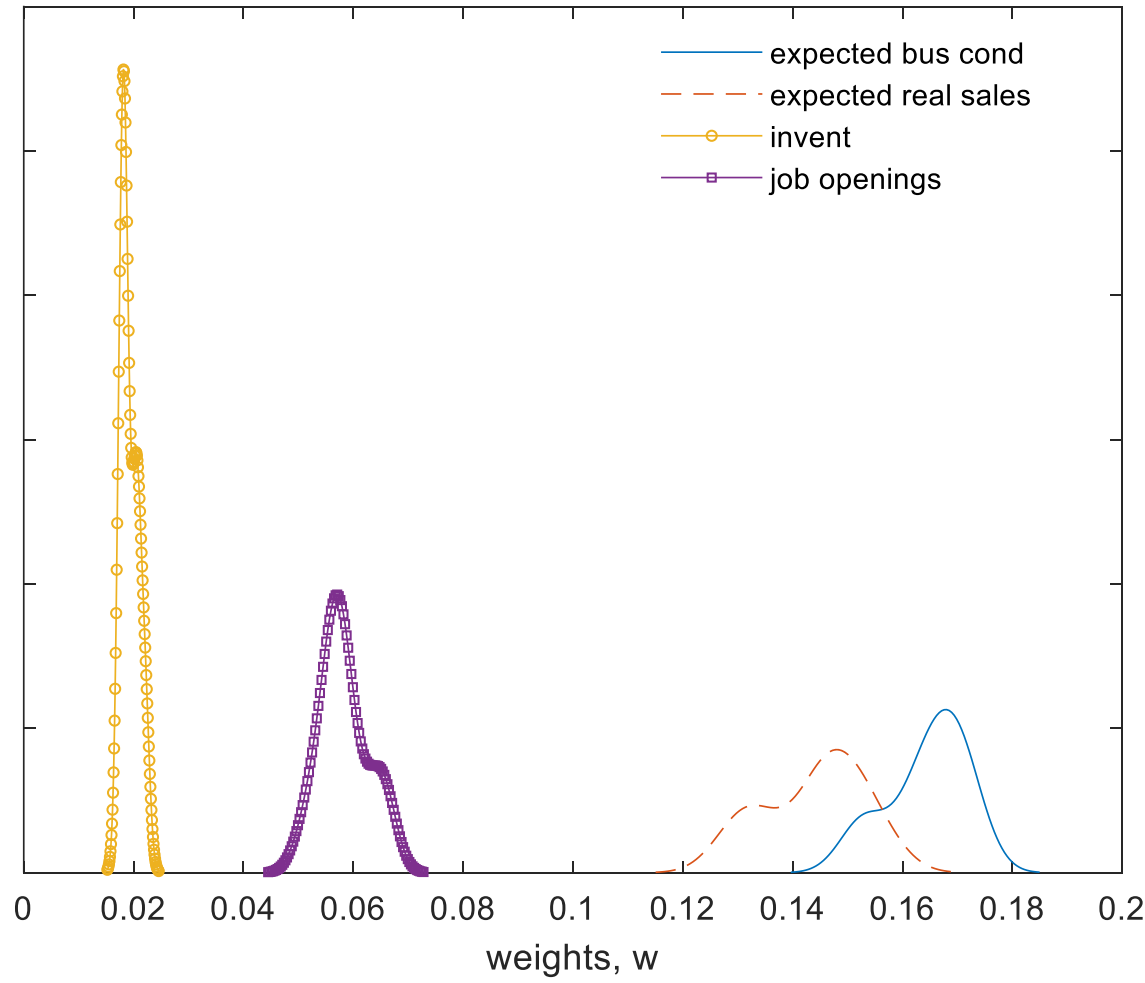


(c)

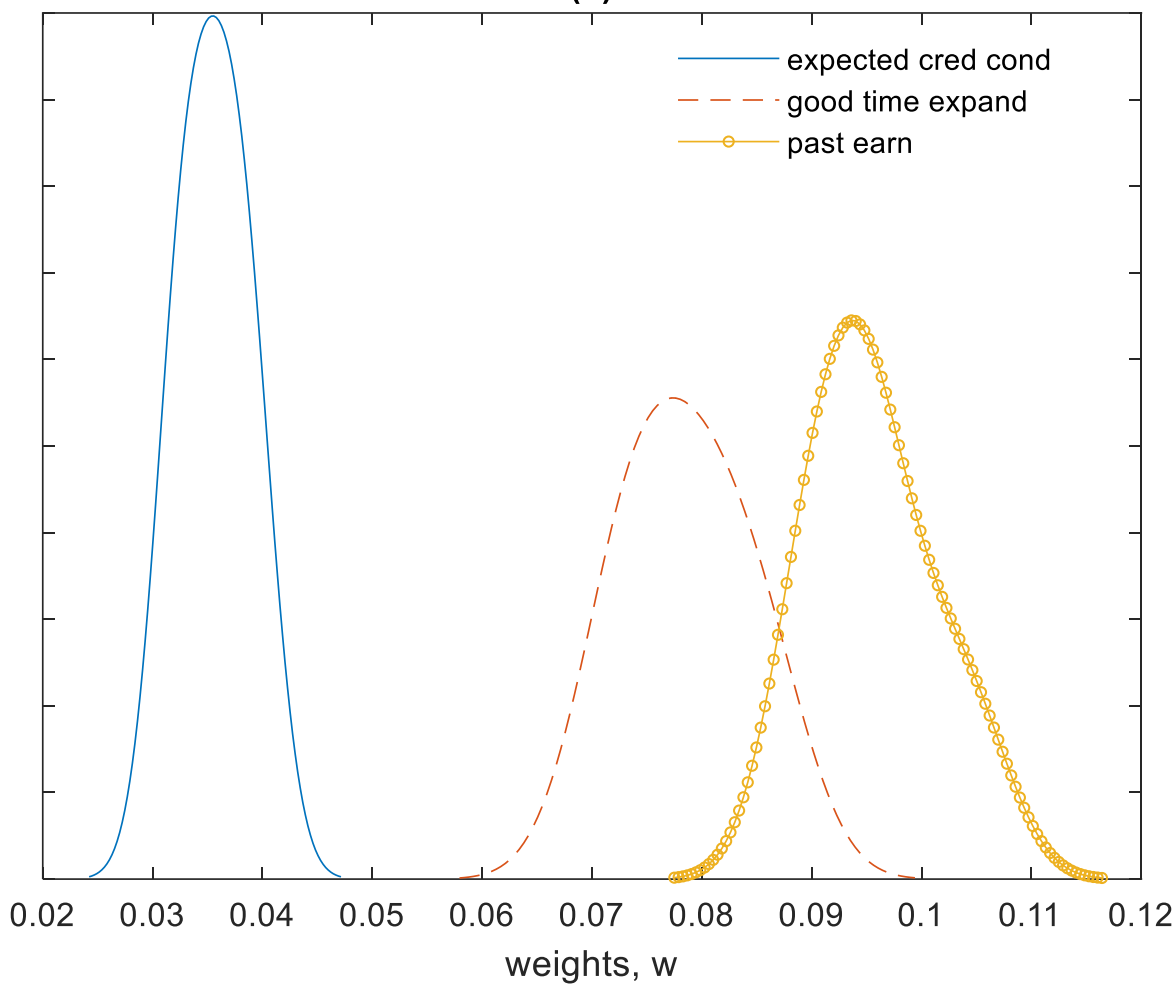

(d)

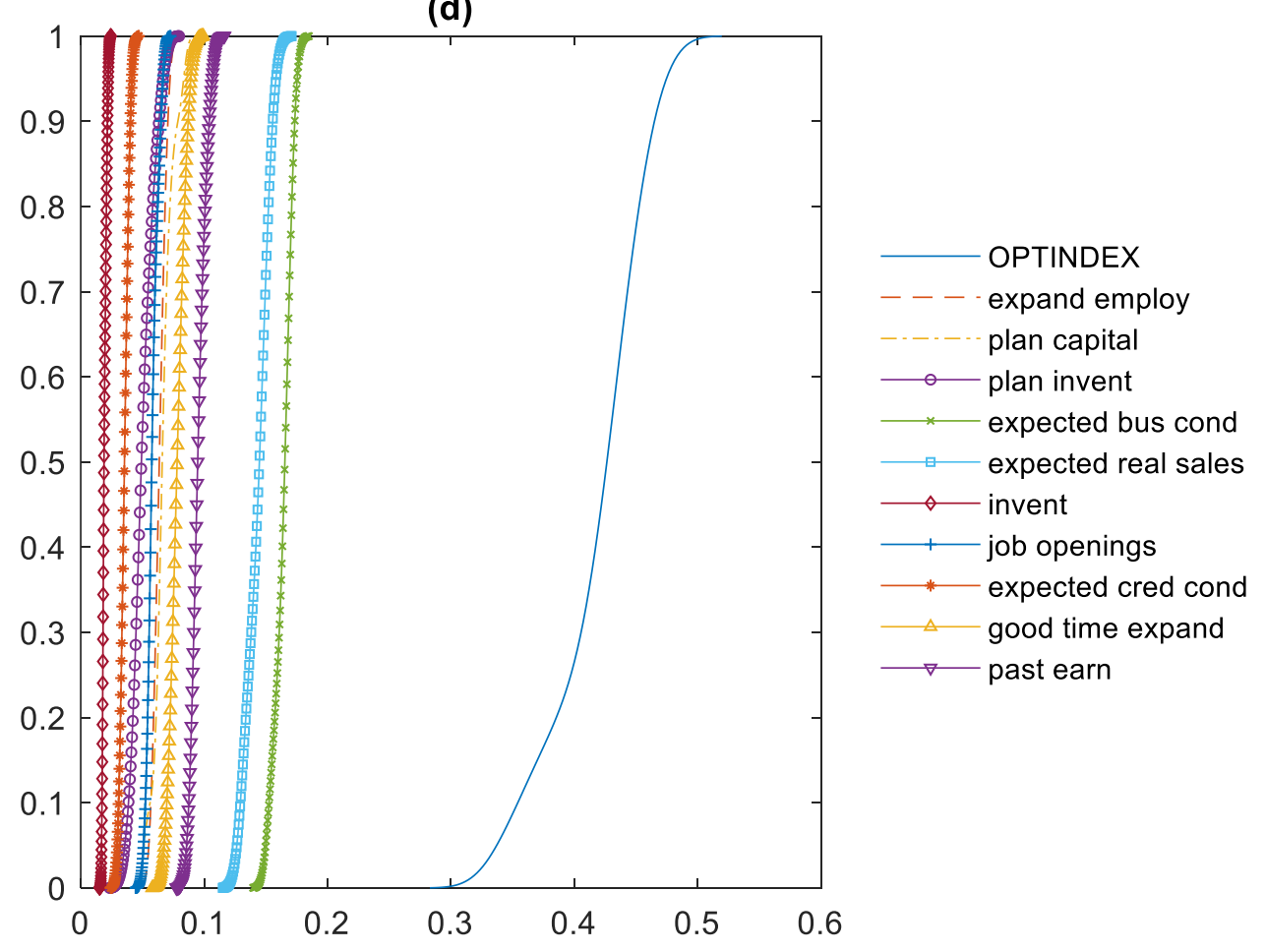

Notes: In panel (d) we report the posterior cdf's to understand ordering relations between the weights. Here, OPTINDEX seems to be associated with the largest weight, followed by expan_employment, etc. 
Figure 2. Posterior mean estimates of the modified composite indicator

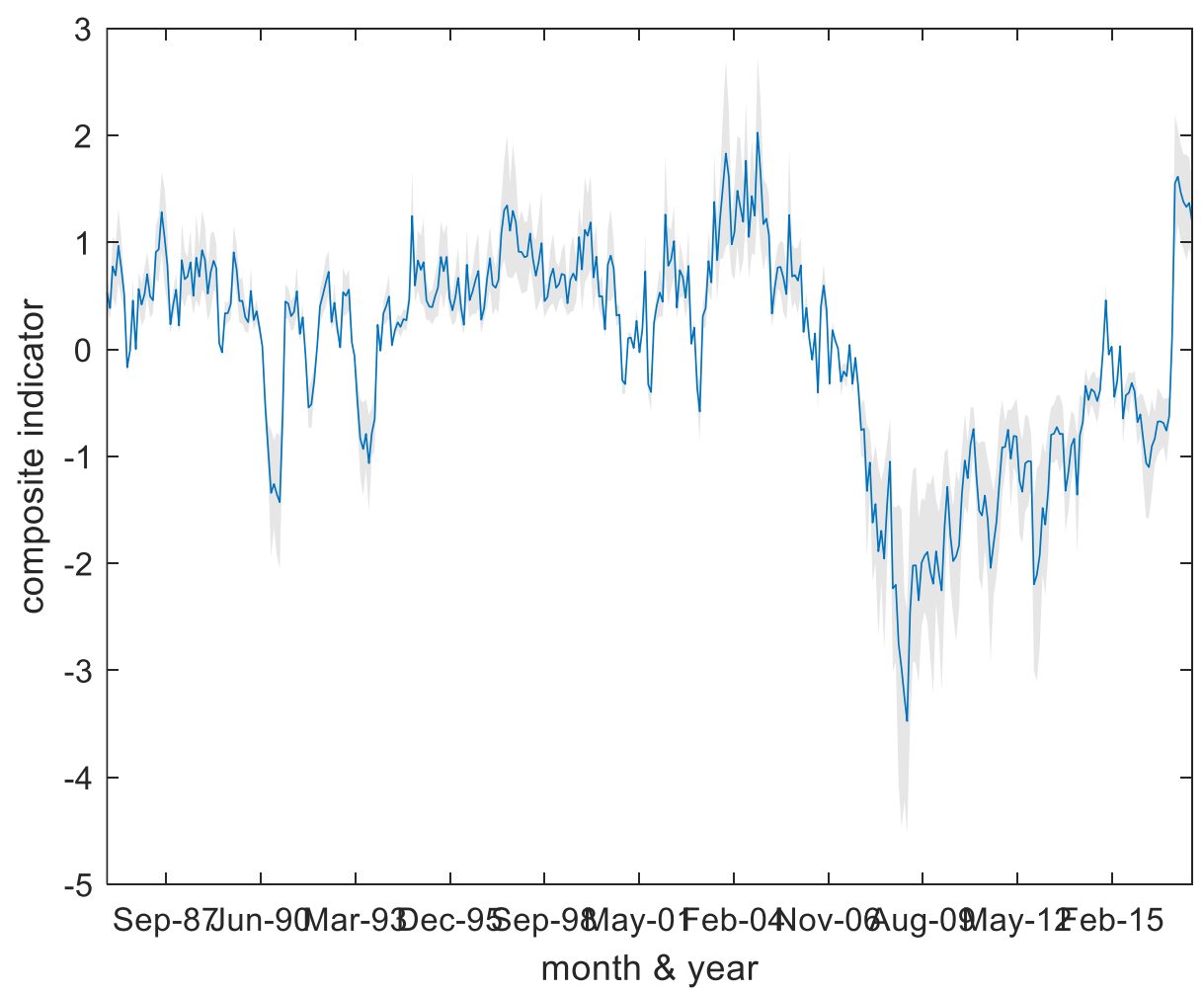

Notes: The Figure presents the posterior mean estimate of the composite indicator. Also shown is the $95 \%$ Bayes probability interval. 
Figure 3. Posterior mean policy inefficiency

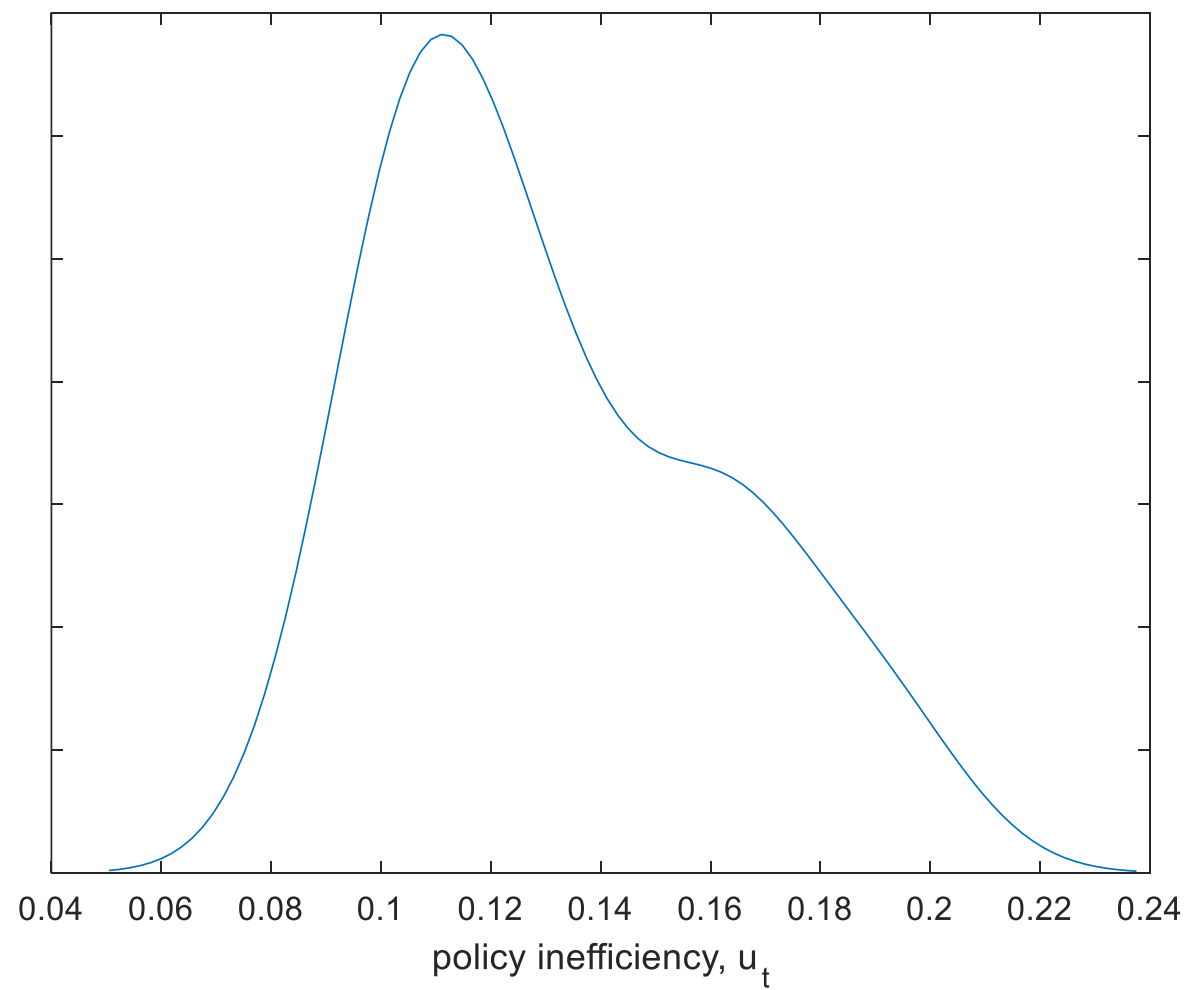

Notes: The Figure presents the sample distribution of posterior mean estimates of inefficiency. The mean, median and s.d. are 0.132, 0.122, and 0.031, respectively. Inefficiency is estimated as $\bar{u}_{t}=S_{t}^{-1} \sum_{s=1}^{S} u_{t}^{(s)}$ where $\left\{u_{t}^{(s)}, s=1, \ldots, S\right\}$ is a sample of size $S$ from the posterior of the model. 


\section{Online Appendix A}

\section{MCMC methods}

We remind that we use the prior in (9) and (10). Since we apply the LASSO prior separately to the composite indicator equation and the inefficiency equation we need two $\lambda$ coefficients (say $\lambda_{1}$ and $\lambda_{2}$ ) as well as two different $\boldsymbol{\tau}$ vectors, say $\boldsymbol{\tau}_{1}$ and $\boldsymbol{\tau}_{2}$. Our prior is

$$
\begin{array}{r}
p\left(\boldsymbol{w}, \rho, \boldsymbol{\beta}, \psi_{o}, \psi, \boldsymbol{\gamma}, \sigma_{v}, \sigma_{u}, \sigma_{\varepsilon}, \lambda_{1}, \lambda_{2}, \boldsymbol{\tau}_{1}, \boldsymbol{\tau}_{2}\right) \\
\propto \sigma_{v}^{-1} \sigma_{u}^{-1} \sigma_{\varepsilon}^{-1} I_{h b b S}(\boldsymbol{w}),
\end{array}
$$

where $I_{\mathbb{S}}(\boldsymbol{w})=1$ if $\boldsymbol{w} \in \mathbb{S}$, and zero otherwise. Denote $\theta=$ $\left[\boldsymbol{w}, \rho, \boldsymbol{\beta}, \psi_{o}, \psi, \boldsymbol{\gamma}, \sigma_{v}, \sigma_{u}, \sigma_{\varepsilon}, \lambda_{1}, \lambda_{2}, \boldsymbol{\tau}_{1}, \boldsymbol{\tau}_{2}\right]$. The posterior distribution has the following density:

$$
\begin{gathered}
p\left(\theta,\left\{u_{t}\right\}_{t=1}^{n},\left\{y_{t}^{*}\right\}_{t=1}^{n} \mid \boldsymbol{Y}\right) \propto \\
\sigma_{\varepsilon}^{-(n+1) / 2} \exp \left\{-\frac{1}{2 \sigma_{\varepsilon}^{2}} \sum_{t=1}^{n}\left(\boldsymbol{y}^{\prime}{ }_{t} \boldsymbol{w}-y_{t}^{*}\right)^{2}\right\} . \\
\sigma_{v}^{-(n+1) / 2} \exp \left\{-\frac{1}{2 \sigma_{v}^{2}} \sum_{t=1}^{n}\left(y_{t}^{*}+u_{t}-\rho y_{t-1}^{*}-\boldsymbol{x}_{t}{ }^{\prime} \boldsymbol{\beta}\right)^{2}\right\} . \\
\sigma_{u}^{-(n+1) / 2} \exp \left\{-\frac{1}{2 \sigma_{u}^{2}} \sum_{t=1}^{n}\left(\ln u_{t}-\psi_{o}-\psi_{1} \ln u_{t-1}-\boldsymbol{x}^{\prime}{ }_{t} \boldsymbol{\gamma}\right)^{2}-\sum_{t=1}^{n} \ln \right. \\
p\left(\rho, \boldsymbol{\beta} \mid \boldsymbol{D}_{\boldsymbol{\tau}_{1}}, \lambda_{1}\right) \cdot p\left(\psi_{o}, \psi_{1}, \boldsymbol{\gamma} \mid \boldsymbol{D}_{\boldsymbol{\tau}_{2}}, \lambda_{2}\right) .
\end{gathered}
$$

For the prior $p\left(\rho, \boldsymbol{\beta} \mid \boldsymbol{D}_{\tau_{1}}, \lambda_{1}\right)$ we have

$$
\boldsymbol{\delta} \mid \boldsymbol{D}_{\boldsymbol{\tau}_{1}}, \lambda_{1} \sim \mathcal{N}\left(\mathbf{0}, \boldsymbol{D}_{\boldsymbol{\tau}_{1}}\right) \lambda_{1}^{K} \prod_{j=1}^{K+1} e^{-\lambda_{1} \tau_{1, j}^{2}}
$$

where $\boldsymbol{\delta}=\left[\rho, \boldsymbol{\beta}^{\prime}\right]^{\prime}, \boldsymbol{\tau}_{1}=\left[\tau_{1, j}, j=1, \ldots, K+1\right]$.

For the prior $p\left(\psi_{o}, \psi_{1}, \boldsymbol{\gamma} \mid \boldsymbol{D}_{\tau_{2}}, \lambda_{2}\right)$ we have

$$
\boldsymbol{\vartheta} \mid \boldsymbol{D}_{\boldsymbol{\tau}_{2}}, \lambda_{2} \sim \mathcal{N}\left(\mathbf{0}, \boldsymbol{D}_{\boldsymbol{\tau}_{2}}\right) \lambda_{1}^{K+1} \prod_{j=1}^{K+2} e^{-\lambda_{1} \tau_{2, j}^{2},}
$$

where $\boldsymbol{\vartheta}=\left[\psi_{o}, \psi_{1}, \boldsymbol{\gamma}^{\prime}\right]^{\prime}, \boldsymbol{\tau}_{2}=\left[\tau_{2, j}, j=1, \ldots, K+2\right]$.

The conditional posterior distributions are as follows ${ }^{3}$.

$$
\begin{gathered}
\frac{\sum_{t=1}^{n}\left(\boldsymbol{y}_{t}{ }_{t} \boldsymbol{w}-y_{t}^{*}\right)^{2}}{\sigma_{\varepsilon}^{2}} \mid \cdot \boldsymbol{Y} \sim \chi_{n}^{2} \\
\frac{\sum_{t=1}^{n}\left(y_{t}^{*}+u_{t}-\rho y_{t-1}^{*}-\boldsymbol{x}_{t}{ }^{\prime} \boldsymbol{\beta}\right)^{2}}{\sigma_{v}^{2}} \mid \cdot \boldsymbol{Y} \sim \chi_{n}^{2}, \\
\frac{\sum_{t=1}^{n}\left(\ln u_{t}-\psi_{o}-\psi_{1} \ln u_{t-1}-\boldsymbol{x}^{\prime}{ }_{t} \boldsymbol{\gamma}\right)^{2}}{\sigma_{u}^{2}} \mid \cdot \boldsymbol{Y} \sim \chi_{n}^{2} .
\end{gathered}
$$

The posterior conditional distribution of $\left[\rho, \boldsymbol{\beta}^{\prime}\right]^{\prime}=\boldsymbol{\delta}$ is

$$
\boldsymbol{\delta} \mid \cdot \boldsymbol{Y} \sim \mathcal{N}\left(\widehat{\boldsymbol{\delta}}, \boldsymbol{V}_{\delta}\right)
$$

where $\widehat{\boldsymbol{\delta}}=\left(\mathbb{X}^{\prime} \mathbb{X}+\sigma_{v}^{2} \boldsymbol{D}_{\boldsymbol{\tau}}^{-1}\right)^{-1} \mathbb{X}^{\prime}(\boldsymbol{y}+\boldsymbol{u}), \mathbb{X}=\left[y_{t-1}^{*}, \boldsymbol{x}_{t}^{\prime}\right], \quad \boldsymbol{y}=\left[y_{1}, \ldots, y_{n}\right]^{\prime}, \quad \boldsymbol{u}=$

\footnotetext{
${ }^{3}$ We use $\mid \cdot, \boldsymbol{Y}$ to denote conditioning on all other parameters and the data $\boldsymbol{Y}$.
} 
$\left[u_{1}, \ldots, u_{n}\right]^{\prime}$, and $\boldsymbol{V}_{\delta}=\sigma_{v}^{2}\left(\mathbb{X}^{\prime} \mathbb{X}+\sigma_{v}^{2} \boldsymbol{D}_{\boldsymbol{\tau}}^{-1}\right)^{-1}$.

The posterior conditional distribution of $\left[\psi_{o}, \psi_{1}, \boldsymbol{\gamma}^{\prime}\right]^{\prime}=\boldsymbol{\vartheta}$ is

$$
\vartheta \mid \cdot, \boldsymbol{Y} \sim \mathcal{N}\left(\widehat{\boldsymbol{\vartheta}}, \boldsymbol{V}_{\vartheta}\right)
$$

where $\widehat{\boldsymbol{\vartheta}}=\left(\mathbb{Z}^{\prime} \mathbb{Z}+\sigma_{u}^{2} \boldsymbol{D}_{\boldsymbol{\tau}}^{-1}\right)^{-1} \mathbb{Z}^{\prime} \ln \boldsymbol{u}$, where $\mathbb{Z}=\left[1, \ln u_{t-1}, \boldsymbol{x}_{t}^{\prime}\right], \quad \boldsymbol{V}_{\vartheta}=\sigma_{u}^{2}\left(\mathbb{Z}^{\prime} \mathbb{Z}+\right.$ $\left.\sigma_{u}^{2} \boldsymbol{D}_{\boldsymbol{\tau}}^{-1}\right)^{-1}$.

Finally, the posterior conditional posterior of $\boldsymbol{w}$ is given as follows.

$$
\begin{gathered}
\boldsymbol{w} \mid \cdot, \boldsymbol{Y} \sim \mathcal{N}\left(\widehat{\boldsymbol{w}}, \boldsymbol{V}_{w}\right), 0 \leq w_{m} \leq 1, m=1, \ldots, M, \sum_{m=1}^{M} w_{m} \\
=1,
\end{gathered}
$$

where $\widehat{w}=\left(\mathbb{Y}^{\prime} \mathbb{Y}\right)^{-1} \mathbb{Y}^{\prime} \boldsymbol{y}^{*}, \mathbb{Y}=\left[y^{\prime}{ }_{t}\right], \boldsymbol{y}^{*}=\left[y_{1}^{*}, \ldots, y_{n}^{*}\right]^{\prime}$. This is acomplished using the algorithm of Altmann, McLaughlin, and Dobigeon (2014).

The conditional posterior of $y_{t}^{*}$ is

$$
y_{t}^{*} \mid \cdot, Y \sim \mathcal{N}\left(\hat{y}_{t}^{*}, \sigma^{2}\right),
$$

where $\hat{y}_{t}^{*}=\frac{\sigma_{v}^{2} \boldsymbol{y}_{t}{ }^{\prime} \boldsymbol{w}-\sigma_{\varepsilon}^{2} R_{t}}{\sigma_{v}^{2}+\sigma_{\varepsilon}^{2}}, \sigma^{2}=\frac{\sigma_{v}^{2} \sigma_{\varepsilon}^{2}}{\sigma_{v}^{2}+\sigma_{\varepsilon}^{2}}, R_{t}=u_{t}-\rho y_{t-1}^{*}-\boldsymbol{x}_{t}{ }^{\prime} \boldsymbol{\beta}$.

Finally, to draw $\left\{u_{t}\right\}_{t=1}^{n}$ we notice that the distribution in terms of $\ln u_{t}$ is logconcave for each $t \in\{1, \ldots, n\}$. For each $t$, we find the mode and the second derivative at the mode. In turn, we generate candidates from a univariate normal distribution whose mean is the mode and its variance is given by minus the inverse of the second derivative. We apply rejection sampling using this distribution to obtain a draw from $\ln u_{t} \mid \cdot, \boldsymbol{Y}$.

Finally, we can draw $\lambda_{1}, \lambda_{2}$ from their respective conditional posteriors (which are gamma) and the elements of $\boldsymbol{\tau}_{1}$ and $\boldsymbol{\tau}_{2}$ can be drawn as in (Park \& Casella, 2008). 
Online Appendix B

\section{Components of NFIB Small Business Optimism Index}

1. Plans to Increase Employment

2. Plans to Make Capital Outlays

3. Plans to Increase Inventories

4. Expect Economy to Improve

5. Expect Real Sales Higher

6. Current Inventory

7. Current Job Openings

8. Expected Credit Conditions

9. Now a Good Time to Expand

10. Earnings Trends 


\section{Online Appendix C}

\section{Term Sets by Category of Policy Uncertainty}

[Source: https://www.policyuncertainty.com/categorical_terms.html]

Monetary policy - federal reserve, the fed, money supply, open market operations, quantitative easing, monetary policy, fed funds rate, overnight lending rate, Bernanke, Volcker, Greenspan, central bank, interest rates, fed chairman, fed chair, lender of last resort, discount window, European Central Bank, ECB, Bank of England, Bank of Japan, BOJ, Bank of China, Bundesbank, Bank of France, Bank of Italy

Taxes - taxes, tax, taxation, taxed

Fiscal Policy and Government spending - government spending, federal budget, budget battle, balanced budget, defense spending, military spending, entitlement spending, fiscal stimulus, budget deficit, federal debt, national debt, Gramm-Rudman, debt ceiling, fiscal footing, government deficits, balance the budget

Health care - health care, Medicaid, Medicare, health insurance, malpractice tort reform, malpractice reform, prescription drugs, drug policy, food and drug administration, FDA, medical malpractice, prescription drug act, medical insurance reform, medical liability, part d, affordable care act, Obamacare

National security - national security, war, military conflict, terrorism, terror, 9/11, defense spending, military spending, police action, armed forces, base closure, military procurement, saber rattling, naval blockade, military embargo, no-fly zone, military invasion

Entitlement programs - entitlement program, entitlement spending, government entitlements, social security, Medicaid, medicare, government welfare, welfare reform, unemployment insurance, unemployment benefits, food stamps, afdc, tanf, wic program, disability insurance, part d, oasdi, Supplemental Nutrition Assistance Program, Earned Income Tax Credit, EITC, head start program, public assistance, government subsidized housing

Regulation - regulation, banking supervision, glass-steagall, tarp, bank supervision, thrift supervision, dodd-frank, financial reform, commodity futures trading commission, cftc, house financial services committee, basel, capital requirement, Volcker rule, bank stress test, securities and exchange commission, sec, deposit insurance, fdic, fslic, ots, occ, firrea, truth in lending, union rights, card check, collective bargaining law, national labor relations board, nlrb, minimum wage, living wage, right to work, closed shop, wages and hours, workers compensation, advance notice requirement, affirmative action, at-will employment, overtime requirements, trade adjustment assistance, davis-bacon, equal employment opportunity, eeo, osha, antitrust, competition policy, merger policy, monopoly, patent, copyright, federal trade commission, ftc, unfair business practice, cartel, competition law, price fixing, class action, healthcare lawsuit, tort reform, tort policy, punitive damages, medical malpractice, energy policy, energy tax, carbon tax, cap and trade, cap and tax, drilling restrictions, offshore drilling, pollution controls, environmental restrictions, clean air act, clean water act, environmental protection agency, epa, immigration policy 
Financial Regulation - banking supervision, glass-steagall, tarp, bank supervision, thrift supervision, dodd-frank, financial reform, commodity futures trading commission, cftc, house financial services committee, basel, capital requirement, Volcker rule, bank stress test, securities and exchange commission, sec, deposit insurance, fdic, fslic, ots, occ, firrea, truth in lending

Trade policy - import tariffs, import duty, import barrier, government subsidies, government subsidy, wto, world trade organization, trade treaty, trade agreement, trade policy, trade act, doha round, uruguay round, gatt, dumping

Sovereign debt, currency crises - sovereign debt, currency crisis, currency crash, currency devaluation, currency revaluation, currency manipulation, euro crisis, Eurozone crisis, european financial crisis, european debt, asian financial crisis, asian crisis, Russian financial crisis, Russian crisis, exchange rate 


\section{Online Appendix D \\ EMV volatility tracker components}

[Source: https://www.policyuncertainty.com/EMV_monthly.html]

The () create an overall EMV tracker by first specifying three word sets:

$\mathrm{E}:\{$ economic, economy, financial $\}$

M: $\{$ "stock market", equity, equities, "Standard and Poors" (and variants)\}

$\mathrm{V}:\{$ volatility, volatile, uncertain, uncertainty, risk, risky\}

Thereafter, they obtained monthly count of newspaper articles with atleast one term on E, M and V for eleven major U.S. newspapers: the Boston Globe, Chicago Tribune, Dallas Morning News, Houston Chronicle, Los Angeles Times, Miami Herald, New York Times, San Francisco Chronicle, USA Today, Wall Street Journal, and Washington Post. The raw EMV counts are scaled by count of all articles in the same newspaper in during the month. The resulting estimate is further scaled by frequency of counts for each newspaper to create a unit standard deviation during the period of observation. The standardized scale counts are then averaged by newspapers by month, and then resulting estimate is multiplicatively rescaled by mean value of VIX. For category related EMV, the share of EMV articles in each category are multiplied by the current period EMV tracker value.

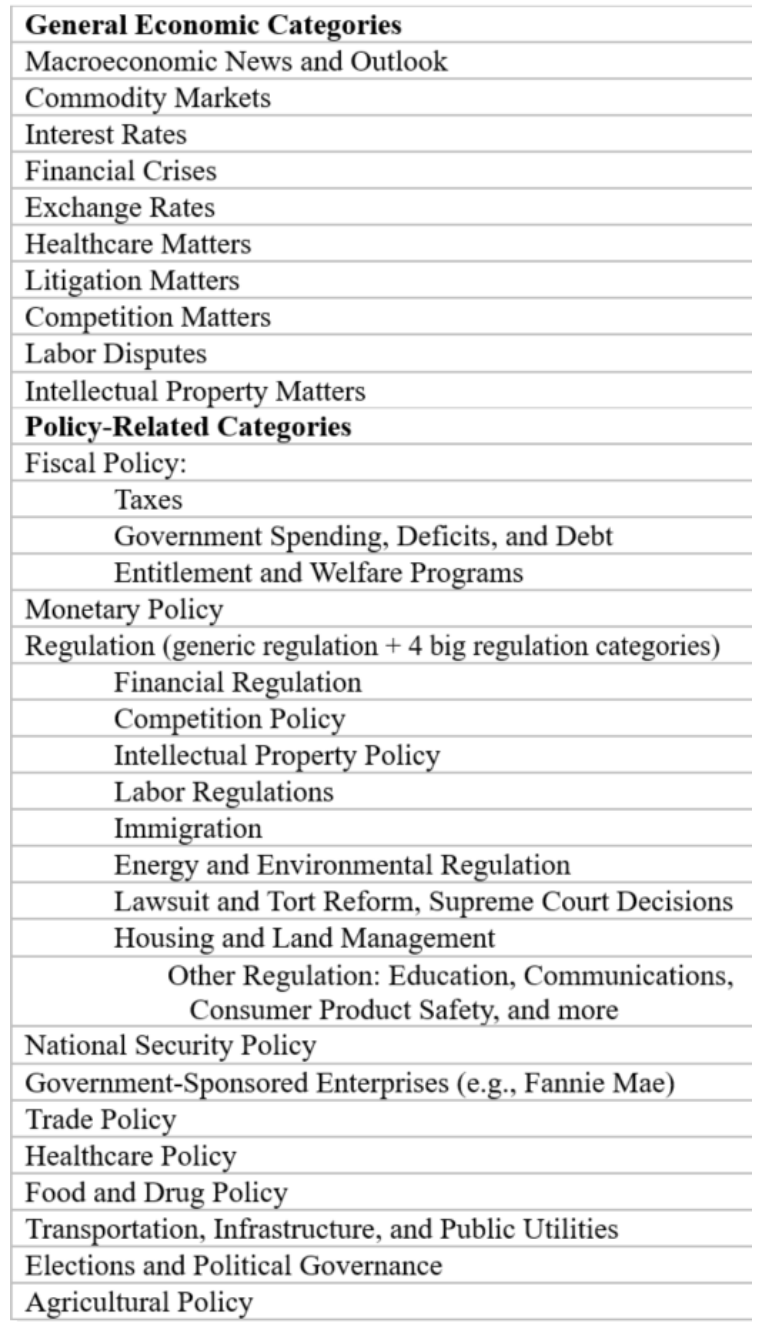




\section{Online Appendix E}

Table E.1. Results from a standard dynamic factor model

(1)

VARIABLES

Dynamic Factor Model

Lagged factor

$0.778 * * *$

Economic Policy Uncertainty

$(0.0379)$

Economic Policy Uncertainty

$-0.000809$

$(0.00373)$

Monetary policy

0.00183

$(0.00134)$

Fiscal Policy (Taxes OR Spending)

$-0.0135^{*}$

(0.00703)

Taxes

$0.0103 * *$

(0.00502)

Government spending

$-0.000109$

(0.00127)

Health care

$-0.000322$

National security

(0.000791)

0.000639

(0.00109)

Entitlement programs

0.000689

(0.000878)

Regulation

0.000921

(0.00120)

Financial Regulation

$-0.00131 * * *$

(0.000442)

Trade policy

0.000433

(0.000660)

Sovereign debt, currency crises

$-0.000145$

$(0.000170)$

0.00528

Overall EMV Tracker

(0.0364)

Policy-Related EMV Tracker

$-0.0576$

(0.0486)

Macroeconomic News and Outlook EMV

$-0.0209$

Tracker

$(0.0538)$

$-0.0184$

Macroeconomic Broad Quantity Indicators EMV

$(0.0275)$

Macroeconomic Inflation EMV Indicator

0.0163

$(0.0304)$

Macroeconomic Interest Rates EMV Tracker

$0.0510 *$

$(0.0305)$

Macroeconomic Other Financial Indicators EMV

$-0.0243$

Tracker

(0.0999)

Macroeconomic Labor Markets EMV Tracker

$-0.00265$ 
Macroeconomic Real Estate Markets EMV

$(0.0343)$

Tracker

0.00965

Macroeconomic Trade EMV Tracker

$(0.0252)$

0.0408

(0.133)

Macroeconomic Business Investment and

$0.223^{*}$

Sentiment EMV Tracker

$(0.121)$

Macroeconomic Consumer Spending and

$-0.0231$

Sentiment EMV Tracker

$(0.0482)$

Commodity Markets EMV Tracker

$-0.0551 * *$

$(0.0252)$

0.0250

Financial Crises EMV Tracker

(0.0264)

Exchange Rates EMV Tracker

0.0232

(0.0643)

Healthcare Matters EMV Tracker

$-0.190$

(0.141)

Litigation Matters EMV Tracker

0.0982

(0.104)

Competition Matters EMV Tracker

0.0218

(0.0813)

Labor Disputes EMV Tracker

$-0.0333$

(0.0738)

Intellectual Property Matters EMV Tracker

$-0.0210$

(0.112)

0.0879

Fiscal Policy EMV Tracker

$(0.0591)$

Taxes EMV Tracker

0.00190

(0.0549)

Government Spending, Deficits, and Debt EMV

0.0195

Tracker

(0.0517)

Entitlement and Welfare Programs EMV Tracker

$-0.0135$

$(0.0611)$

Monetary Policy EMV Tracker

$-0.0390$

$(0.0280)$

Regulation EMV Tracker

0.0785

$(0.0561)$

$-0.0439$

Financial Regulation EMV Tracker

$(0.0656)$

Competition Policy EMV Tracker

0.00444

(0.0728)

$-1.331 * *$

Intellectual Property Policy EMV Tracker

(0.587)

$-0.0975$

Labor Regulations EMV Tracker

(0.140)

Immigration EMV Tracker

$-0.446^{*}$ 
Energy and Environmental Regulation EMV

$(0.269)$

Tracker

Lawsuit and Tort Reform, Supreme Court

(0.145)

$-0.247^{*}$

Decisions EMV Tracker

(0.149)

Housing and Land Management EMV Tracker

$-0.0740$

(0.141)

Other Regulation EMV Tracker

$-0.251$

(0.182)

National Security Policy EMV Tracker

$-0.00315$

$(0.0307)$

Government-Sponsored Enterprises EMV

$0.0866 * *$

Tracker

Trade Policy EMV Tracker

$(0.0364)$

0.190

(0.115)

Healthcare Policy EMV Tracker

0.231

(0.178)

Food and Drug Policy EMV Tracker

0.219

(0.218)

Transportation, Infrastructure, and Public

0.197

Utilities EMV Tracker

(0.193)

Elections and Political Governance EMV Tracker

0.00266

(0.0344)

0.395

Agricultural Policy EMV Tracker

$(0.408)$

Global Economic Policy Uncertinaty (GEPU)

$-0.00102$

current

$(0.00147)$

Constant

$0.326 * *$

(0.162)

Observations

246

R-squared 